\title{
Perdagangan Di Bali Utara Zaman Kerajaan Bali Kuno Perspektif Geografi Kesejarahan
}

\author{
Ketut Sedana Arta ${ }^{1}$ \\ ${ }^{1}$ Universitas Pendidikan Ganesha, Bali
}

\section{A R T I C L E I N F O}

Article history:

Received 14 Desember 2019

Accepted 23 Desember 2019

Available online 31

\section{Kata Kunci:}

Perdagangan, Bali Utara,

Geografi sejarah

Keywords:

Historical Geography
Desember 2019

Commerce, North Bali,

\begin{abstract}
A B S T R A K
Penelitian ini bertujuan untuk menganalisis pengaruh lingkungan geografis terhadap perdagangan di Kerajaan Bali Kuno dan bentuk perdagangan yang telah dikembangkan oleh masyarakat pada masa Kerajaan Bali Kuno. Jenis penelitian ini adalah penelitian eksplorasi. Penelitian ini menggunakan teknik studi kepustakaan. Data yang telah terkumpul selanjutnya dianalisis secara deskriptif. Hasil penelitian menunjukkan bahwa perdagangan Bali Utara terbagi menjadi dua yaitu perdagangan dalam pulau dan antar pulau. Perdagangan dalam pulau menghubungan pelabuhan di Bali Utara. Perdagangan antarsuler dibuktikan dengan ditemukannya temuan gerabah Arikemedu, bahanbahan perunggu, keramik Cina. Hubungan dagang tersebut dimulai zaman perundagian sehingga mantapnya hubungan dagang ini melalui proses yang panjang.
\end{abstract}

\section{A B S T R A C T}

This study aims to analyze the influence of the geographical environment on trade in the Kingdom of Ancient Bali and the forms of commerce that have been developed by the people during the era of the Ancient Bali Kingdom. This type of research is exploratory research. This research uses literature study techniques. The collected data is then analyzed descriptively. The results showed that the North Bali trade was divided into two, namely, trade within islands and between islands. Trading on the island connects the port in North Bali. Intersular trade is evidenced by the discovery of Arikemedu earthenware, bronze materials, and Chinese ceramics. The trade relations began the era of perundagian so that the stable trade relations through a long process.

Copyright @ Universitas Pendidikan Ganesha. All rights reserved.

\footnotetext{
* Corresponding author.

E-mail addresses: sedana.arta@undiksha.ac.id
} 


\section{Pendahuluan}

Sebagai kajian yang belum ber-kembang di Indonesia, Geografi Kesejarahan harus disokong oleh beberapa data disiplin kemasalaluan di luar disiplin geografi itu sendiri. Data yang telah berhasil diungkap oleh arkeologi, sejarah, antropologi, geologi, ekologi dan lainnya sudah selayaknya di-perhatikan dalam kajian geografi sejarah. (Butlin, 1993) menyatakan "geografi sejarah" adalah kajian geografis tentang masa lampau atau study of the geographies of past time. Kajian tersebut dilakukan melalui rekonstruksi imajinatif dalam suatu rentang waktu dengan menekankan pada pemahaman integratif terhadap dinamika kehidupan dalam suatu area. Adapun hal yang menjadi pusat perhatian dalam kajian geografi sejarah adalah fenomena atau proses keruangan yang menggambarkan dinamika keterkaitan antara manusia-lingkungan antara lain dalam hal memanfaatkan sumberdaya alam, membangun permukiman, mengembangkan kekuasaan, mengontrol teritori, dan sebagainya.

Peristiwa sejarah di masa lampau tentunya melibatkan masyarakat manusia dalam setting suasana alam tertentu, dalam lingkungan geografi tertentu. Oleh karena itu interaksi antara manusia yang membuat sejarah serta keadaan alam fisiknya mutlak pernah terjadi di masa silam. Hingga sekarang kajian-kajian arkeologi, sejarah, dan antropologi acapkali hanya memperhatikan dari sisi budayanya saja yang diperbuat oleh masyarakat manusia, dan gambaran geografis sezaman agaknya terlupakan. Dengan adanya kajian khusus terhadap geografi sejarah yang mendukung terjadinya peristiwa sejarah di masa silam diharapkan kajian tentang masyarakat dan kebudayaannya dalam interaksi dengan lingkungan geografis sebagai "panggung teater" nya, dapat lebih memperluas pemahaman yang telah ada selama ini (Munandar, 2013).

Satu hal yang penting pula untuk diperhatikan adalahmasalah mata pencaharian hidup dari masyarakat pembuat sejarah di lingkungan geografis tertentu. Mata pencaharian masyarakat masa lalu dapat pula mengungkapkan masalah stratifikasi sosial, fungsi distribusi yang berkaitan dengan kondisi geografis, dunia politik, pendidikan, bahkan cara-cara mempertahankan diri dari musuhnya. Dengan kata lain, studi geografi kesejarahan bukan hanya sekedar menghasilkan atlas sejarah, atau atlas perkembangan aspek kebudayaan tertentu disuatu wilayah, namun yang penting adalah pemerian yang luas dan mendalam dari atlas/peta yang telah dihasilkannya itu.

Studi sejarah Indonesia sampai sekarang masih mengutamakan wilayah-wilayah di bagian barat Indonesia (Jawa, Sumatera, Sulawesi), dan sangat sedikit mengenai Indonesia bagian Timur atau Selatan. Hal ini mungkin karena daerah Indonesia bagian timur dianggap kering, sedikit berkembang, kurang data, selain sejarawan yang memang berasal dari daerah bagian Barat, yang menyebabkan mereka mungkin lebih tertarik melakukan penelitian di bagian Barat Hal ini dapat pula dicermati dari buku-buku teks sejarah yang masih didominasi oleh sejarah di Indonesia bagian Barat, termasuk sejarah Bali Utara yang kaya dengan peninggalan sejarah zaman kerajaan Bali Kuna.

Bali merupakan salah satu dari untaian pulau-pulau di nusantara yang membentang dari Barat ke Timur, yaitu dari Sumatera sampai ke Timor. Untaia tersebut menyerupai jembatan sehingga memudahkan akses masuknya manusia maupun hewan menyeberang dari satu pulau ke pulau lainnya pada masa lalu. Secara astronomis terletak pada posisi titik kordinat: 7050' dan $8^{\circ} 3^{\prime}$ Lintang Selatan (Z.B) dan di antara 114⒉ $6^{\prime}$ dan $115^{\circ} 43$ Bujur Timur (O,L). Seperti halnya daerah-daerah lainnya di Indonesia termasuk di daerah katulistiwa yang beriklim trofis yang ditandai dengan siklus musim hujan berkisar pada bulan oktober sampai dengan April dn paruhnya adalah musim kemarau karena dipengaruhi oleh angina muson (Arsana, 2014:15)

Di tengah-tengah Pulau Bali terbentang pegunungan dari arah barat ke timur sehingga menggambarkan relief dan topografi Pulau Bali yang terbagi menjadi dua yakni Bali bagian utara disebut Den Bukit dan bagian selatan disebut Delod Bukit. Bali utara secara geografis posisinya sangat strategis arena memiliki pelabuhan-pelabuhan alam. Buktinya adalah masih banyaknya pelabuhan sampai saat ini seperti pelabuhan Sangsit (Rahman, 2017). Hasil penelitian yang dilaksanakan oleh para pakar menunjukkan bahwa Bali Utara secara geografis letaknya sangat strategis, maka kontak-kontak dagang hubungan antara Bali dengan Jawa lebih intensif berlangsung sekitar wilayah Bali Utara. Di samping itu kondisi laut di bagian utara relatif 
kondusif bagi perjalanan perahu-perahu yang menggunakan sistem teknologi navigasi yang masih sederhana. Hal itu dapat ditunjukkan dari adanya pelabuhan-pelabuhan alam di wilayah pesisir utara seperti Sangsit, Buleleng, Temukus, Gilimanuk, Pangkuk Paruk, Tanjung Ser, Pacung dan Sembiran. Keseluruhan pelabuhan yang ada tersebut merupakan pintu masuk dan jalur perdagangan kuno di Bali Utara yang menghubungkan dengan daerah lainnya di nusantara (Yudiana, 2013).

Hasil-hasil penelitian dari Balar Denpasar juga menunjukkan bahwa sekitar Gilimanuk, Pangkung Paruk, Sembiran, Pacung yang digolongkan sebagai situs pesisir menunjukkan buktibukti adanya hubungan perdagangan dengan dunia luar pada masa prasejarah di Bali. Situs pacung dan Sembiran merupakan pintu masuk ke Bali sejak abad I hingga XII Masehi merupakan salah satu pelabuhan alam kuna di Bali yang penting (Ardika, 1991). Di situs Bali Utara juga ditemukan adanya kultus Putri Ayu Mas Subandar. Hal ini terkait denga penguasaan perdagangan di pantai Utara Bali pada zaman Kerajaan Bali Aga, yaitu pada zaman pemerintahan jayapangus dengan istrinya dari Cina bernama Kang Cheng Wie yang nantinya dijadikan istri kedua (Pageh, 2017). Peran Putri Cina ini sangat besar, bahkan mewarnai pemerintahan selanjutnya. Pewarisannya dengan pembuatan pura bersama, bernama Pura Gambur Anglayang disebut juga pura Kertanegara yang sekarang terletak di Kubutambahan Buleleng, sebagai pemersatu para pedagang dari berbagai etnik bangsa yang ikut berdagang di bali Utara, antara lain Ratu mekah, ratu Sundawan, Ratu Ayu Syah Subandar, Dalem Pingit. Hampir semua pelabuhan kuno dilengkapi dengan Pura Syahbandar, sebagai pemujaan Ratu Ayu Mas Subandar yang menguasai perdagangan. Ini menjadi bukti bahwa perdagangan yang hidup sudah ada jauh bahkan mungkin sudah ada sejak zaman praaksara (Sholeh, 2019).

Dalam prasasti -prasasti Bali Kuna diuraikan tentang pelabuhan-pelabuhan Bali Kuno. Prasasti Sembiran A IV (1065 M) lembar IX b menyebutkan jika ada saudagar dari seberang laut dating dengan perahu kecil, perahu besar berlabuh di Manasa yang merapat datangnya, biaya merapat maksimal 1 masaka, dan harganya dilebihkan bagi orang terkemuka, tidak dikenai sumbangan pengawasan, dan tidak ada pemaksaan, jika mereka menunjukkan surat perintah membayar biaya berlabuh yang dtulis oleh paduka raja. Mengacu pada isi prasasti tersebut Bali Utara memegang peranan yang penting dalam perdagangan secara intersuler dan antarsuler kerajaan Bali Kuno dengan kerajaan-kerajaan di nusantara maupun luar negeri. Termasuk juga adanya tiga pelabuhan penting yang pernah dijadikan pelabuhan utama oleh Kerajan Buleleng yakni pelabuhan Buleleng, Sangsit dan Temukus (Astiti, 2018). Dalam konteks ini akan dibahas tentang pengaruh lingkungan geografis terhadap perdagangan di Kerajaan Bali Kuno dan bentuk perdagangan yang telah dikembangkan oleh masyarakat pada masa Kerajaan Bali Kuno.

\section{Metode Penulisan}

Metode penulisan yang digunakan yaitu studi kepustakaan dengan menggali data-data melalui buku-buku, artikel/jurnal, internet sebagai bahan analisis. Bahan akan dianalisis secara kualitataif berdasarkan teori kemudian disajikan secara sistematis secara deskriptif. Adapun data-data telah dikumpulkan kemudian digunakan untuk menulis Perdagangan di Utara Bali Utara zaman Bali kuno Perpektif Geografi Kesejarahan.

\section{Hasil dan Pembahasan}

Pulau Bali terletak di antara Pulau Jawa dan Pulau Nusa Tenggara Barat (lihat juga: Kondisi Geografis Pulau Jawa). Wilayah pulaunya memiliki luas sebesar $5.636 \mathrm{~km}^{2}$. Pulau Bali di bagian Timur berbatasan dengan Selat Lombok dan Pulau Nusa Tenggara Barat. Sedangkan di Barat berbatasan dengan Selat Bali dan Provinsi Jawa Timur. Sedangkan di bagian Utara berbatasan dengan Laut Bali dan sebelah selatan berbatasan dengan Samudera Indonesia. Panjang ruas pantai Kabupaten Buleleng sekitar 144 km, 19 km-nya melewati kecamatan Tejakula

Bali dikenal sebagai surga tropis yang ada di Indonesia. Iklim Bali adalah iklim tropis dimana pergantian musimnya dipengaruhi oleh angin musim yang berubah setiap 6 bulan sekali. Sama seperti musim yang terjadi di Indonesia secara umum, Provinsi Bali mengalami musim penghujan pada Bulan Oktober-April dan musim kemarau mulai dari April hingga Oktober. 
Untuk curah hujan rata-rata di Bali adalah $127 \mathrm{~mm} /$ bulan. Sedangkan temperatur udaranya bervariasi mulai dari $24^{\circ}-38^{\circ} \mathrm{C}$. Pulau Bali adalah bagian dari Kepulauan Sunda Kecil sepanjang $153 \mathrm{~km}$ dan selebar $112 \mathrm{~km}$ sekitar 3,2 km dari Pulau Jawa. Secara astronomis, Bali terletak di 8 25' 23" Lintang Selatan dan $115^{\circ} 14^{\prime} \quad 55^{\prime \prime}$ Bujur Timur yang membuatnya beriklim tropis seperti bagian Indonesia yang lain.

Berdasarkan relief dan topografi, di tengah-tengah Pulau Bali terbentang pegunungan yang memanjang dari barat ke timur dan di antara pegunungan tersebut terdapat gugusan gunung berapi yaitu Gunung Batur dan Gunung Agung serta gunung yang tidak berapi, yaitu Gunung Merbuk, Gunung Patas dan Gunung Seraya. Adanya pegunungan tersebut menyebabkan Daerah Bali secara Geografis terbagi menjadi 2 (dua) bagian yang tidak sama yaitu Bali Utara dengan dataran rendah yang sempit dan kurang landai dan Bali Selatan dengan dataran rendah yang luas dan landai. Kemiringan lahan Pulau Bali terdiri dari lahan datar (0-2\%) seluas 122.652 ha, lahan bergelombang (2-15\%) seluas 118.339 ha, lahan curam (15-40\%) seluas 190.486 ha dan lahan sangat curam ( $>40 \%$ ) seluas 132.189 ha. Provinsi Bali memiliki 4 (empat) buah danau yang berlokasi di daerah pegunungan, yaitu Danau Beratan, Buyan, Tamblingan dan Danau Batur.

Perdagangan pada masa Bali Kuno dapat dilihat berdasarkan adanya istilah-istilah berkaitan dengan perdagangan di dalam prasasti. Seperti adanya istilah pkěn untuk sebutan pasar, adanya sebutan ser pasar adalah jabatan yang bertugas sebagai kepala pasar, yang memungkinkan jabatan ini mengatur transaksi perdagangan, disamping itu jabatan ini juga mengawasi keamanan pasar demi kedaulatan kerajaan. Adanya nama-nama hari pasar seperti Pasar Wijaya Pura, Pasar Wijaya Manggala dan Pasar Wijaya Kranta, serta adanya istilah saudagar baik laki-laki (wanigrama) dan saudagar perempuan (wanigrami). Selain itu adanya istilah kepala atau pejabat yang mengurus semua kepentingan yang disebut dengan juru wanigrama dan juru wanigrami. Para pedagang umumnya disebut dengan banyaga atau wanyaga dibawah pimpinan juru wanyaga. Banyaga adalah pedagang besar yang melakukan perdagangan antarpulau dan mungkin melakukan perdagangan internasional, sedangkan pedagang eceran atau kecil disebut dengan istilah atanja, manghalu, dan adagang (Destriana, 2014). Melalui sumber prasasti inilah dapat diketahui informasi mengenai perdagangan, khususnya pada masa Bali Kuno.

Ramai tidaknya pelabuhan dapat tergantung dari berbagai faktor. Di antaranya yang terpenting adalah faktor ekologi sebagai faktor determinan. Pelabuhan yang baik adalah jika kapal dapat berlabuh dengan aman, terlindung dari ombak yang besar, angin, dan arus yang kuat (Poesponegoro, Marwati, \& Nugroho, 2009). Tempat yang paling ideal bagi pelabuhan adalah di sebatang sungai, agak jauh ke dalam. Akan tetapi lebar dan kedalaman sungai membatasi perkembangan pelabuhan bersangkutan.

Pelabuhan dalam aktivitasnya mempunyai peran penting dan strategis untuk pertumbuhan industri dan perdagangan serta merupakan segmen usaha yang dapat memberikan kontribusi bagi pembangunan nasional.Hal ini membawa konsekuensi terhadap pengelolaan segmen usaha pelabuhan tersebut agar pengoperasiannya dapat dilakukan secara efektif, efisien dan profesional sehingga pelayanan pelabuhan menjadi lancar, aman, dan cepat dengan biaya yang terjangkau. Pada dasarnya pelayanan yang diberikan oleh pelabuhan adalah pelayanan terhadap kapal dan pelayanan terhadap muatan (barang dan penumpang). Secara teoritis, sebagai bagian dari mata rantai transportasi laut, fungsi pelabuhan adalah tempat pertemuan (interface) dua moda angkutan atau lebih serta interface berbagai kepentingan yang saling terkait. Barang yang diangkut dengan kapal akan dibongkar dan dipindahkan ke moda lain. Sebaliknya barang yang diangkut dengan truk atau kereta api ke pelabuhan bongkar akan dimuat lagi ke kapal. Oleh sebab itu berbagai kepentingan saling bertemu di pelabuhan seperti perbankan, perusahaan pelayaran, bea cukai, imigrasi, karantina, syahbandar dan pusat kegiatan lainnya. Atas dasar inilah dapat dikatakan bahwa pelabuhan sebagai salah satu infrastruktur transportasi, dapat membangkitkan kegiatan perekonomian suatu wilayah karena merupakan bagian dari mata rantai dari sistem transportasi maupun logistik.

Pertanyaan yang sering muncul adalah mengapa pelabuhan-pelabuhan kuno di Bali Utara khususnya di Sembiran, Pacung dan Julah mengalami kemunduran, padahal berdasarkan 
sebaran artepak diperoleh melalui ekskavasi di Sembiran, Pacung, dan Julah menunjukkan bahwa kawasan itu dan sekitarnya telah menjadi pemukiman dan sekaligus penguburan jauh sebelum prasasti diterbitkan. Bahkan pada masa itu telah terjadi kontak budaya dengan duia luar khususnya bidang perdagangan. Temuan artefak berupa gerabah India berhiaskan rolet dan berasosiasi manik-manik. Adanya kontak budaya semacam ini mendorong perubahan social dalam kehidupan masyarakat yang mengarah pada suatu tatanan kehidupan masyarakat yang semakin konpleks. Dengan semakin konpleksnya kehidupan masyarakat, maka diperlukan tatanan hukum yang dapat dipakai untuk menstabilkan kondisi kehidupan masyarakat (Ardika, 1989). Eksistensi Desa Julah, Sembiran, Pacung mempunyai peranan penting dalam perdagangan dapat dicermati dari Prasasti Sembira,, prasasti Kintamani D yang berangka tahun 1200 Masehi, menyebutkan bahwa hanya penduduk Kintamani yang boleh berjualan kapas di Desa Julah, Buhundalem, Peminggir dan Les. Demikian pula dalam prasasti Sembiran IV terdapat kata baniaga, pedagang yang dating dengan perahu atau sampan ke Dea manasa (Ardika, 1989, 1991).

Namun perdagangan di Sembiran dan Julah serta pacung mengalami kemunduran, hal ini dimungkinkan ada dua factor yang menyebabkan yakni faktor keamanan karena dalam beberapa prasasti disebutkan Desa Julah diserang oleh para perompak sehingga penduduknya ada yang terbunuh da nada yang melarikan diri, bisa jadi juga disebabkan adanya pendangkalan pelabuhan karena factor pencucian tanah, hal ini berlaku juga pada kerajaan Sri Wijaya yang terletak di Palembang. Menurut Daljoeni (1984) di daerah dimana curah hujan meresap masuk ke dalam tanah dan sebagian lagi mengalir melalui permukaan tanah menuju ke sungai-sungai. Air hujan yang meresap ke dalam tanah tak sedikit sehingga dapat melarut habis bahan-bahan kesuburan tanah dan mengangkutnya ke lapisan bawah tanah tak dapat dicapai oleh akar-akar tetumbuhan. Bagian atas dari tanah tercuci kesuburannya dan dapat menjadi tandua, ini yang disebut pemiskinan tanah secara kimiawi. Disamping itu ada pencucian secara fisis yang dikerjakan oleh sebagian air hujan yang tidak ikut meresap ke dalam tanah tetapi mengalir melalui permukaan bumi masuk ke dalam sungai-sungai. Top soil berisi humus menjadi hanyut olehnya dan daerah yang bersangkutan kehilangan kesuburannya. Akibat pencucian tanah inilah yang mungkin dialami oleh Kerajaan Sri Wijaya sehingga meruntuhkannya.

Kemunduran kualitas tanah ini pasti ikut melatarbelakangi keruntuhan Sri Wijaya; karena beras semakin langka dan perlu impor tentunya, tetapi pelabuhan-pelabuhan mengalami pendangkalan karena endapan sungai dan proses kenaikan tanah. Seperti diketahui letak Lampung, Plembang, dan jambi terletak di atas deretan geantiklinal, sebagai imbangan terhadap geosinklinal (yang menurunkan tanah) disepanjang pantai barat Sumatera. Intinya kemunduran Kerajaan Sri Wijaya sebah utamanya adalah pendangakalan pelabuhan Sri Wijaya.

Mengacu pada kasus di Kerajaan Sri Wijaya kemunduran fungsi pelabuhan yang ada di Pacung, bisa jadi disebabkan adanya pendangakalan pelabuhan karena faktor pencucian tanah oleh air hujan pada perbukitan di selatan Sembiran, Julah dan Pacung sehingga pedagangpedagang dari luar tidak lagi bisa menambatkan perahunya di dermaga dan mengalihkan perdagangannya di Manasa (Pantai Bungkulan). Padahal menurut (Ardika, 1991) pelabuhan yang ada di Pacung sebagai pusat pelabuhan dan pemukiman telah memenuhi factor-faktor yang telah dipersyaratkan seperti: pemilihan lokasi pemukiman erat kaitannya dengan kondisi lingkungan, tersdianya sumber air dan fasiltas-fasilitas yang diperlukan untuk transfortasi, tersedianya sumber daya alam yang memberikan kemudahan pangan sehingga manusia mampu beradaftasi dengan lingkungan, dan tidak terlepas ari kemahiran teknologi dan aktivitas ekonomi masyarakatnya.

Bukti bahwa Pacung pernah menjadi pusat pelabuhan dan pemukiman mengacu pada hasil ekskavasi yang dilakukan tahun 2008 pada kotak VIII yang terdiri dari fragmen gerabah lokal, fragmen gerabah India, fragmen keramik, fragmen perunggu, arang, sisa organik berupa tulang binatang dan gigi binatang, serta moluska. Dari temuan tersebut yang paling banyak adalah gerabah, dan satu gerabah yang masih utuh, dengan pola hias terajala dengan teknk tekan. Priuk-priuk bulat seperti ini sangat banyak ditemukan di situs Gilimanuk yang terletak di bagian barat pesisir utara Bali diperkirakan berasal dari masa perundagian atau pra Hindu. 
Priuk-priuk bulat pada umumnya berupa bekal kubur yang ditempatkan dekat dengan kerangka manusia (Hidayah, Ati, Sumerata, \& Keling, 2017).

Gerabah-gerabah India teknik pembuatannya lebih maju dibandingkan dengan gerabah lokal, hal ini dapat dilihat dari teknik hias dengan teknik gores yang halus dan tajam. Gerabahgerabah India terutama gerabah Rolet dikategorikan berasal dari abad ke-1 Masehi (Ardika, 1989). Dengan demikian pacung dan sekitarnya telah melakukan kontak perdagangan antar daerah dan dengan daerah-daerah luar terutama India. Data ini juga menguatkan apa yang tercantum dalam Prasasti Kintamani C yang menyebutkan antara lain pertemuan para saudagar bertemu di manasa dengan menggunakan transfortasi air "jukung atau perahu" (Goris, 1954).

\subsection{Perdagangan di Bali Utara}

Bali Utara merupakan daerah yang memiliki pelabuhan alam yang tersebar dari Gilimanuk, Celukan Bawang, Tanjung Ser, Pangkung Paruk, Manasa, Pacung dan Sembiran. Pelabuhan alam tersebut terhindar dari ombak besar sehingga kapal-kapal pedagang dari berbagai daerah dan negara-negara (seperti India, Arab, Cina) bisa berlabuh memuat bongkar perdagangannya di pelabuhan-pelabuhan tersebut (Astiti, 2018).

Prasasti-prasasti yang merekam aktivitas perdagangan menunjukkan bahwa sudah terdapat struktur dalam perdagangan di pelabuhan. Seperti yang tertuang dalam prasasti Bebetin A1 (896 M) disebutkan “...anada banyaga turun ditu...panien di hyangapi...” Artinya jika ada para saudagar (seberang pulau) yang baru dating di sana (kota pelabuha Julah) agar yang bersangkutan didaftar dan dikenakan kewajiban (pajak) untuk bangunan suci Hyang Api. Selanjutnya dinyatakan".ada mati ya tua banyaga, parduan drbyanya prakara..." atinya jika ada saudagar (seberang pulau) yang meninggal disana, agar harta warisannya di bagi dua. Selain itu, dalam prasasti Pengotan A1 (924 M) juga ada disebutkan"Juru Wanyaga" atau Juru Banyaga (Goris, 1954: 67) yang artinya petugas pemerintah yang khususnya mengurusi para saudagar asing yang ada di Bali pada saat itu. Kemudian dalam prasasti Sembiran B (955 M) menyebutkan banigrama (skt banigrama) yang artinya pedagang atau saudagar timah

Prasasti Sembiran A IV (1065 M) disebutkan"...mangkana yan hana banyaga sakeng sabrang jong, bahitra, camunduk I manasa hatpani katkananya, wnanga ikanang karaman patrakasihana, wlyana hatep mulyan ma I anglipahana sargha mahajana..." artinya jika ada saudagar dari seberang laut dating merapat dengan perahu dan bahitra di pelabuhan, agar warga desa sekitar memberikan belas kasih padanya, biaya merpat maksimal 1 masaka, dan harganya dilebihkan bagi orang terkemuka/terpandang, tidak dikenai sumbangan pengawasan (pacasaku) dan tidak ada pemaksaan.

Mengacu pada isi prasasti tersebut, nampaknya Bali Utara merupakan jalur perdagangan internasional, hal tersebut dimungkinkan karena Bali Utara memiliki pelabuhan sebagai bandar transito, seperti pelabuhan Julah, Pacung dan Sembiran di Buleleng Timur yang berkembang abad ke -10 Masehi, kemudian pelabuhan laut mengalami pergeseran ke barat di manasa (daerah bungkulan). Perpindahan ini secara geografis bisa jadi disebabkan adanya pendangkalan dari pelabuhan Julah dan juga oleh factor keamanan karena beberapa kali diberitakan dalam prasasti adanya penyerangan ke Julah oleh perompak.

Bukti lain yang menunjukkan bahwa Bali Utara adalah pusat perdagangan adalah adanya bangunan pelinggih yang terkait dengan penguasa perdagangan secara niskala, bangunan itu disebut dengan beberapa nama seperti Ratu Ayu Subandar, Ratu Ngurah Subandar, Ratu Ulang Alu yang ditemukan di beberapa pura di Bali. Di Pura Batur Kintamani ada pelinggih terkait dengan perdagangan bernama Ratu Ngurah Subandar, Di Pura Besakih ada pelinggih bernama Ida Ratu Ayu Subandar. Di Pura dalem Balingkang terdapat pelinggih Ida ratu Ngurah Subandar, semua pelinggih tersebut didedikasikasikan untuk memuja atau memuliakan Dewa Perdagangan.

Kata Subandar mengingatkan kita pada Syahbandar yang berasal adri bahasa Persia yang berarti raja atau kepala pelabuhan, sedang kata ulang alu mengingatkan kita pada kata ngalu yang mengacu pada pedagang Bali masa lalu yang menjajakan dagangan dari pasar ke desa-desa baik berjalan kaki maupun naik kuda. 
Data-data terkait dengan perdagangan di Bali Utara dapat dicermati dari temuan uang emas, uang kepeng, uang perak pada situs-situs arkeologi di Ume Jero, Tamblingan, dan Kalibukbuk. Selain berupa uang, pecahan keramik ataupun keramik utuh dari Dinasti Cina juga menunjukkan aktivitas perdagangan dengan dunia internasional, karena pembuatan keramik menjadi salah satu artepak yang memiliki ciri-ciri asal pembuatannya dan kronologinya (Harkantiningsih, 2010).

Secara garis besar, perdagangan di Bali ddibedakan menjadi perdagangan alam negeri (intersuler) dan luar negeri (antarsuler). Perdagangan dalam negeri (Bali Dwipa mandala) beberapa kali disebutkan dalam prasasti, seperti ada kata pken, sedangkan pimpinan pasar disebut Ser Pasar (Setiawan, 1977). Tampaknya pasar-pasar tersebut adalah pasar lokal atau pasar desa yang terletak di daerah-daerah produksi. Selain pasar lokal terdapat pula pasar yang terletak dekat puri dan pada pemukiman yang padat. Pada prasasti Dausa Pura Bukit Indrakila A1 ada bangunan pasar yang disebut dengan bangunen pasar, sedangkan dalam prasasti Sukawana A1 ada yang disebut lagad pasar. Menurut Goris (1954) istilah lagad pasar merupakan bangunan untuk melakukan tempat melakukan transaksi jual beli di pasar. Komoditi yang diperdagangkan antara lain padi, bawang merah, bawang putih, kacang hijau, dan kapas. Produk peternakan yang diperjualbelikan adalah sapi, kerbau, kambing, kuda, babi, ayam, itik dan berbagai jenis ikan.

Perdagangan anatara Bali Utara dengan para pedagang di Kintamani dan daerah pedalaman lain seperti penduduk di sekitar Danau Tamblingan dan Beratan dapat dianalisis dari isi prasasti Gobleg Pura Batur B dan prasasti Tamblingan Pura Endek IV yang menyebutkan keterkaitan daerah-daerah pegunungan ini khususnya dengan Manasa (Suarbhawa, 2009). Sementara perdagangan antar pulau melalui jalur laut melalui pelabuhan pesisir Bali Utara seperti yang terungkap dalam prasasti sembiran A IV sebagai berikut:..."mangkana yan hana banyaga sakeng sabrang jong, bahitara, camunduk I manasa hatpani katkanannya wnanga ikanang karaman patrakasihana uliyana hatep mulyan ma I anglepihana sargha mahajana tan papacasuka, tan kna paksa ya, ika ta yan pamana sang hyang ajna haji tinumbuk lelek paduka haji. Artinya"...jika ada saudagar dari seberang laut dating dengan perahu kecil, perahu besar berlabuh di Manasa yang merapat datangnya, biaya merapat maksimal 1 masaka, dan harganya dilbihkan bagi orang terkemuka, tidak dikenai sumbangan pengawasan, dan tidak ada pemaksaan, jika mereka menunjukkan surat perintah membayar biaya berlabuh yang ditulis oleh paduka raja.

Eksistensi Pelabuhan Julah di Bali Utara pada bagian prasasti disebutkan:"...saluwirannya tan pangal pangduka, kebo, sapi, wdus, celeng,, tumurun irikanang pasisi I Julah..." Artinya: tidak mendapat halangan untuk menurunkan hewan seperti kerbau, sapi, kambing, babi, di pesisir pantai Desa Julah. Hal ini menyiratkan bahwa para saudagar berdatangan berlabuh di pesisir Julah melakukan transaksi dengan mata dagangan berbagai jenis hewan serta beraneka barang lain (Suarbhawa, 2009).

Perdagangan antar pulau juga terekam dalam prasasti Ujung (962 Saka) sebagai berikut:"...lawan yan hanakanya mare Jawa, mare Gurun saparannya mare desa tara (desantara) mare ngalaparawu saluwirnya tan knakaramaning jung hyang..."(Goris: 1006). Artinya “...apabila ada penduduk yang hendak berlayar ke Jawa, ke Gurun atau daerah jauh di seberang dengan memakai perahu dan semacamnya, penduduk desa Jung Hyang tidak dikenai pungutan..."

Informasi dari prasasti Sembiran B (873 Saka) bahwa di Desa Julah telah ada perkampungan saudagar (banigrama) di Desa Julah. Ini menunjukkan bahwa Julah adalah Desa Kuno yang memiliki pelabuhan kuno dan memiliki pasar yang representative pada zamannya dibuktikan juga dengan adanya jabatan pasar (serpasar). Demikian pula dengan pelabuhan Manasa, keadaannya tidak jauh dengan pelabuhan Julah. . dalam prasasti Gobleg B, Prasasti Tamblingan Pura Endek IV, Prasasti bengkala disebut di Manasa bermukim para pejabat kerajaan (para nayaka I manasa), bahkan dalam prasasti Trunyan B disebut paduka haji I manasa

Mantapnya perdagangan di Bali Utara tidak terjadi secara tiba-tiba, tetapi melalui proses yang cukup panjang. Indikator adanya perdagangan tersebut adanya temuan gerabah tipe rollet 
dari Arikemendu (India Selatan) di situs Pacung Sembiran yang berasal dari abad pertama masehi. Selain gerabah di situs ini juga ditemukan manik-manik batu karnelian dan manikmanik kaca yang diperkirakan diimpor dari India, demikian pula manik-manik kaca diperkirakan di buat di Asia Tenggara dan bahan bakunya didatangkan dari India atau mediterania (Ardika, 1991).

Demikian pula dengan temuan sejumlah lempengan emas penutup mata telah ditemukan di beberapa rangka di Gilimanuk dan kuburan sarkofagus di Pangkung Lilip (Jemberana), serupa yang ditemukan dibeberapa situs antara lain : situs oton di Pulau Panay (Philipina), santubong (Malaysia), dan kuburan megalitik di situs Adichanallur (India Selatan). Persebaran yang luas ini menunjukkan bahwa adanya kontak perdagangan antara Bali Utara dengan daerah-daerah lain di Asia Tenggara dan India (Ardika, 1991). Kehidupan perdagangan ini bahkan berlanjut pada masa kolonialisme Belanda di Bali Utara dengan dikembangkannya pelabuhan Buleleng sebagai jalur perdagangan penghubung beberapa wilayah di Indonesia Timur dan Tengah (Keling, 2016).

Hasil kajian ini mendukung penelitian Marzuki (2010) yang mengungkapkan bahwa Barang yang diperdagangkan dalam pasar masa Bali Kuno dapat dibedakan menjadi tiga kelompok, yaitu barang kebutuhan sehari-hari, barang produksi pengrajin, dan binatang ternak. Pertama, barang kebutuhan sehari-hari. Berdasarkan data prasasti, barang kebutuhan seharihari yang diperjualbelikan di pasar masa Bali Kuno berupa hasil pertanian dan perkebunan. Awalnya, barangbarang tersebut ditanam untuk keperluan hidup sehari-hari, namun karena jumlahnya yang berlebih sehingga dijual atau ditukarkan dengan barang yang tidak dimiliki. Barangbarang tersebut antara lain, bawang merah, bawang putih, beras, minyak, bumbu, buahbuahan, talas, kemiri, kelapa, dan lain-lain. Selain itu, ada larangan memperjualbelikan dagangan dengan alasan tertentu. Dalam prasasti Bebetin AI (Goris No. 002), disebutkan adanya beberapa barang yang tidak boleh dibeli. Kapas rupanya merupakan primadona utama, hal ini dapat dibuktikan dengan adanya peraturan tentang perdagangan kapas yang dikeluarkan oleh Raja Ekajayalancana. Penduduk Kintamani diberi otonomi dalam penjualan kapas ke daerah pesisir utara Bali, dan tidak ditegur oleh nayakan kapas. Selain barang hasil pertanian dan perkebunan, rupanya pada masa itu sudah diperjualbelikan minuman, yaitu twak (nira). Dalam prasasti Sawan AI (Goris No. 353), disebutkan bahwa pembelian twak (nira) dua pikul, tidak dikenakan pajak pada bulan Kartika.

Kedua, barang produksi kerajinan. Pengrajin pada masa Bali Kuno tinggal berkelompok berdasarkan jenis kerajinan yang dihasilkannya. Kelompok pengrajin pada masa Bali Kuno dapat dibedakan menjadi kelompok pande (pengrajin logam), dan kelompok penjahit pakaian, penenun, tukang celup dan pembuat pola pakaian (mangjahit kajang). Adanya pajak yang dikenakan kepada para pengrajin dapat dijadikan bukti bahwa mereka menghasilkan produk yang cukup banyak untuk kepentingan masyarakat, tidak hanya dipakai sendiri. Dalam prasasti Bebetin AI (Goris No. 002), disebutkan adanya kewajiban membayar pajak bagi pengrajin dan seniman di Banua Baru untuk kepentingan bangunan suci. Barang-barang hasil kerajinan (terutama logam), lebih dominan digunakan dalam upacara persembahan bagi Dewata. (tenunan). Berdasarkan data prasasti, terdapat beberapa hal yang berkaitan erat dengan masalah pakaian, antara lain marundan (menenun), mamangkudhu (mencelup kain menjadi merah), mangnila (mencelup kain menjadi biru), wdihan (pakaian), laway (benang), mangjahit wastra (menjahit pakaian), dan mangjahit kajang (menjahit kain).

Ketiga, binatang ternak dan hasil perikanan. Binatang ternak pada masa Bali Kuno dapat digolongkan dalam ternak besar, unggas, dan binatang berburu. Ternak besar terdiri dari sapi (sapi), kbo/karambo (kerbau), celeng atau centen (babi), wdus (kambing), dan aswa atau asba (kuda). Jenis unggas yang dipelihara berupa hayam atau syap (ayam), puyuh (burung puyuh), daker (sejenis burung), itik (itik), dan hayam sawung (ayam aduan). Sedangkan hewan untuk berburu berupa asu (anjing), dan asu tugì (anjing yang dipotong ekornya). Keberadaan ternak besar (sapi, kerbau) digunakan dalam mengolah pertanian, kuda digunakan untuk transportasi, dan unggas diambil dagingnya dan sebagai binatang piaraan kesayangan. Anjing digunakan untuk berburu binatang di hutan. Pembelian binatang ternak, diatur oleh raja, hal ini dibuktikan 
dengan adanya larangan memperdagangkan binatang tertentu di suatu wilayah dengan alasan tertentu.

Temuan utama dalam kajian ini adalah pelabuhan laut memiliki peranan penting dalam perdagangan. Berdasarkan data prasasti, terdapat beberapa tempat yang diperkirakan sebagai pelabuhan pada masa Bali Kuno. Tempat-tempat yang diduga pelabuhan laut tersebut umumnya terletak di pesisir utara Bali. Pemilihan daerah pesisir utara ini dimungkinkan karena ombak pesisir utara tidak sebesar pesisir selatan.

\section{Simpulan dan Saran}

Antara Geografi dan sejarah memiliki keterikatan yang sangat erat, dimana hubungan tersebut diibaratkan bagai panggung dan lakon, termasuk dalam menganalisis pengaruh geografis terhadap perdagangan pada zaman Bali Kuno di bali Utara. Secara geografis Bali Utara memiliki pelabuhan alam yang baik karena terlindung dari ombak besar dan terdapat teluk dan tanjung serta adanya sumber-sumber air untuk mengisi persediaan air minum bagi para saudagar. Namun dalam perjalanannya terjadi pergeseran, awalnya Julah menjadi pelabuhan representative pada masa Bali Kuno kemudian bergeser ke arah Barat dengan berkembangnya Manasa, Buleleng, Temukus, Celukan Bawang. Pergeseran pusat pusat pelabuhan alam ini disebabkan oleh pendangkalan pelabuhan akibat puncucian tanah yang membawa lumpur dan mengendap di pantai. Perdagangan Bali Utara terbagi menjadi dua yaitu perdagangan dalam pulau dan antar pulau. Perdagangan dalam pulau menghubungan pelabuhan di Bali Utara seperti Julah, pacung, manasa, Tanjung Ser dengan bali di pegunungan bebetin A1, Sembiran A1V, Prasasti Bulian A, Prasasti Gobleg Pura Batur, Prasasti Tamblingan Pura Endek IV. Perdagangan antarsuler dibuktikan dengan ditemukannya temuan gerabah Arikemedu, bahan-bahan perunggu, keramik Cina. Hubungan dagang tersebut dimulai zaman perundagian sehingga mantapnya hubungan dagang ini melalui proses yang panjang.

\section{Daftar Rujukan}

Ardika. (1989). Ekskavasi Arkeologi di Situs Sembiran dan Pacung, Kecamatan Tejakula, Buleleng. Universitas Udayana.

Ardika. (1991). The Beginning of Bronze Metallurgy in Bali. In High Bronze Age I Souheast Asia and South China. Hua Hin, Thailand.

Astiti, I. K. A. (2018). Optimalisasi Pengelolaan Pelabuhan-Pelabuhan Kuno Di Buleleng Dalam Pengembangan Pariwisata. Forum Arkeologi, 31(1), 1-10.

Butlin, R. A. (1993). Historical Geography: Through Gates Of Space And Time. London: Arnold Publisher.

Daljoeni, N. (1984). Geografi Kesejarahan II. Bandung: Alumni.

Destriana, N. (2014). Perdagangan Kapas Pada Masa Bali Kuno Berdasarkan Prasasti Kintamani D Dan E (Kajian Epigrafi). Humanis, 7(2), 1-8.

Goris, R. (1954). Prasasti Bali I. Bandung: Masa Baru.

Harkantiningsih, N. (2010). Perdagangan di Nusantara: Bukti Jaringan Interregional. In Semarak Arkeologi. Bandung.

Hidayah, Ati, Sumerata, W., \& Keling, G. (2017). Potensi Sumberdaya Arkeologi Maritim Di Pesisir Pantai Tejakula, Buleleng, Bali. Berkala Arkeologi SANGKHAKALA, 20(1), 1-10.

Keling, G. (2016). Tipologi Bangunan Kolonial Belanda di Singaraja. Jurnal Arkeologi, 29(2), 6580.

Marzuki, I. W. (2010). Pasar Pada Masa Bali Kuno Abad Ix-Xi Masehi (Kajian Epigrafi). Naditira Widya, 4(2), 282-294.

Munandar, A. A. (2013). Artefak Di Ruang Geografi: Kajian Artefak dalam Geografi Sejarah. Sejarah Dan Budaya, 7(2), 8-15.

Pageh, I. M. (2017). No TitleModel Revitalisasi Ideologi Desa Pakraman Bali Aga Berbasis Kearifan Lokal. Jakarta: Rajawali Pers.

Poesponegoro, Marwati, D., \& Nugroho, N. (2009). Sejarah Nasional Indonesia III ("Zaman Pertumbuhan dan Perkembangan Kerajaan Islam di Indonesia"). Jakarta: Balai Pustaka.

Rahman, D. (2017). Sejarah Perdagangan Antarpulau Sapeken - Sangsit Sebagai Sumber Belajar 
Sejarah. Jurnal Widya Winayata, 8(2), 1-10.

Setiawan. (1977). Sekilas Tentang Perdagangan Pada Masa Bali Kuno: Data Prasasti. (Ardika, Ed.) (Dinamika K). Denpasar: Upada Sastra.

Sholeh, K. (2019). Pelayaran Perdagangan Sriwijaya Dan Hubungannya Dengan Negeri-Negeri Luar Pada Abad VII-IX Masehi. Historia, 7(1), 1-20.

Suarbhawa, I. G. M. (2009). Mata Uang pada Zaman Bali Kuno. Forum Arkeologi, 3(2), 74-87.

Yudiana, I. K. (2013). Peran Etnis Cina Dalam Perdagangan Di Bali Utara Pada Tahun 1850-1942. Historia Vitae, 27(2), 1-10. 